\title{
Convergence Theorems for Maximal Monotone Operators, Weak Relatively Nonexpansive Mappings and Equilibrium Problems
}

\author{
Kamonrat Nammanee, ${ }^{1}$ Suthep Suantai, ${ }^{2,3}$ \\ and Prasit Cholamjiak ${ }^{1,3}$
}

${ }^{1}$ School of Science, University of Phayao, Phayao 56000, Thailand

${ }^{2}$ Department of Mathematics, Faculty of Science, Chiang Mai University, Chiang Mai 50200, Thailand

${ }^{3}$ Centre of Excellence in Mathematics, CHE, Si Ayutthaya Road, Bangkok 10400, Thailand

Correspondence should be addressed to Prasit Cholamjiak, prasitch2008@yahoo.com

Received 13 February 2012; Accepted 9 March 2012

Academic Editor: Rudong Chen

Copyright (C 2012 Kamonrat Nammanee et al. This is an open access article distributed under the Creative Commons Attribution License, which permits unrestricted use, distribution, and reproduction in any medium, provided the original work is properly cited.

We introduce hybrid-iterative schemes for solving a system of the zero-finding problems of maximal monotone operators, the equilibrium problem, and the fixed point problem of weak relatively nonexpansive mappings. We then prove, in a uniformly smooth and uniformly convex Banach space, strong convergence theorems by using a shrinking projection method. We finally apply the obtained results to a system of convex minimization problems.

\section{Introduction}

Let $E$ be a real Banach space and $C$ a nonempty subset of $E$. Let $E^{*}$ be the dual space of $E$. We denote the value of $x^{*} \in E^{*}$ at $x \in E$ by $\left\langle x^{*}, x\right\rangle$. Let $T: C \rightarrow C$ be a nonlinear mapping. We denote by $F(T)$ the fixed points set of $T$, that is, $F(T)=\{x \in C: x=T x\}$. Let $A: E \rightarrow 2^{E^{*}}$ be a set-valued mapping. We denote $D(A)$ by the domain of $A$, that is, $D(A)=\{x \in E: A x \neq \emptyset\}$ and also denote $G(A)$ by the graph of $A$, that is, $G(A)=\left\{\left(x, x^{*}\right) \in E \times E^{*}: x^{*} \in A x\right\}$. A set-valued mapping $A$ is said to be monotone if $\left\langle x^{*}-y^{*}, x-y\right\rangle \geq 0$ whenever $\left(x, x^{*}\right),\left(y, y^{*}\right) \in G(A)$. It is said to be maximal monotone if its graph is not contained in the graph of any other monotone operators on $E$. It is known that if $A$ is maximal monotone, then the set $A^{-1}\left(0^{*}\right)=\{z \in E$ : $\left.0^{*} \in A z\right\}$ is closed and convex.

The problem of finding a zero point of maximal monotone operators plays an important role in optimizations. This is because it can be reformulated to a convex minimization 
problem and a variational inequality problem. Many authors have studied the convergence of such problems in various spaces (see, e.g., [1-16]). Initiated by Martinet [17], in a real Hilbert space $H$, Rockafellar [18] introduced the following iterative scheme: $x_{1} \in H$ and

$$
x_{n+1}=J_{\lambda_{n}} x_{n}, \quad \forall n \geq 1,
$$

where $\left\{\lambda_{n}\right\} \subset(0, \infty), J_{\lambda}$ is the resolvent of $A$ defined by $J_{\lambda}:=J_{\lambda A}=(I+\lambda A)^{-1}$ for all $\lambda>0$, and $A$ is a maximal monotone operator on $H$. Such an algorithm is called the proximal point algorithm. It was proved that the sequence $\left\{x_{n}\right\}$ generated by (1.1) converges weakly to an element in $A^{-1}(0)$ provided that $\liminf _{n \rightarrow \infty} \lambda_{n}>0$. Recently, Kamimura and Takahashi [19] introduced the following iteration in a real Hilbert space: $x_{1} \in H$ and

$$
x_{n+1}=\alpha_{n} x_{n}+\left(1-\alpha_{n}\right) J_{\lambda_{n}} x_{n}, \quad \forall n \geq 1,
$$

where $\left\{\alpha_{n}\right\} \subset[0,1]$ and $\left\{\lambda_{n}\right\} \subset(0, \infty)$. The weak convergence theorems are also established in a real Hilbert space under suitable conditions imposed on $\left\{\alpha_{n}\right\}$ and $\left\{\lambda_{n}\right\}$.

In 2004, Kamimura et al. [20] extended the above iteration process to a much more general setting. In fact, they proposed the following algorithm: $x_{1} \in E$ and

$$
x_{n+1}=J^{-1}\left(\alpha_{n} J\left(x_{n}\right)+\left(1-\alpha_{n}\right) J\left(J_{\lambda_{n}} x_{n}\right)\right), \quad \forall n \geq 1,
$$

where $\left\{\alpha_{n}\right\} \subset[0,1],\left\{\lambda_{n}\right\} \subset(0, \infty)$, and $J_{\lambda}:=J_{\lambda A}=(J+\lambda A)^{-1} J$ for all $\lambda>0$. They proved, in a uniformly smooth and uniformly convex Banach space, a weak convergence theorem.

Let $F: C \times C \rightarrow \mathbb{R}$, where $\mathbb{R}$ is the set of real numbers, be a bifunction. The equilibrium problem is to find $x \in C$ such that

$$
F(x, y) \geq 0, \quad \forall y \in C
$$

The solutions set of (1.4) is denoted by $\mathrm{EP}(F)$.

For solving the equilibrium problem, we assume that

(A1) $F(x, x)=0$ for all $x \in C$,

(A2) $F$ is monotone, that is $F(x, y)+F(y, x) \leq 0$ for all $x, y \in C$,

(A3) for all $x, y, z \in C, \lim \sup _{t \downarrow 0} F(t z+(1-t) x, y) \leq F(x, y)$,

(A4) for all $x \in C, F(x, \cdot)$ is convex and lower semi-continuous.

Recently, Takahashi and Zembayashi [21] introduced the following iterative scheme for a relatively nonexpansive mapping $T: C \rightarrow C$ in a uniformly smooth and uniformly convex Banach space: $x_{1} \in C$ and

$$
\begin{gathered}
C_{1}=C, \\
y_{n}=J^{-1}\left(\alpha_{n} J x_{n}+\left(1-\alpha_{n}\right) J T x_{n}\right),
\end{gathered}
$$




$$
\begin{gathered}
u_{n} \in C \text { such that } F\left(u_{n}, y\right)+\frac{1}{r_{n}}\left\langle y-u_{n}, J u_{n}-J y_{n}\right\rangle \geq 0 \quad \forall y \in C, \\
C_{n+1}=\left\{z \in C_{n}: \phi\left(z, u_{n}\right) \leq \phi\left(z, x_{n}\right)\right\} \\
x_{n+1}=\prod_{C_{n+1}}\left(x_{1}\right), \quad \forall n \geq 1
\end{gathered}
$$

where $\left\{\alpha_{n}\right\} \subset[0,1]$ and $\left\{r_{n}\right\} \subset(0, \infty)$. Such an algorithm is called the shrinking projection method which was introduced by Takahashi et al. [22]. They proved that the sequence $\left\{x_{n}\right\}$ converges strongly to an element in $F(T) \cap \mathrm{EP}(F)$ under appropriate conditions. The equilibrium problem has been intensively studied by many authors (see, e.g., [23-31]).

Motivated by the previous results, we introduce a hybrid-iterative scheme for finding a zero point of maximal monotone operators $A_{i}: E \rightarrow 2^{E^{*}}(i=1,2, \ldots, N)$ which is also a common element in the solutions set of an equilibrium problem for $F$ and in the fixed points set of weak relatively nonexpansive mappings $T_{i}: C \rightarrow C(i=1,2, \ldots)$. Using the projection technique, we also prove that the sequence generated by a constructed algorithm converges strongly to an element in $\left[\bigcap_{i=1}^{N} A_{i}^{-1}\left(0^{*}\right)\right] \cap\left[\bigcap_{i=1}^{\infty} F\left(T_{i}\right)\right] \cap \mathrm{EP}(F)$ in a uniformly smooth and uniformly convex Banach space. Finally, we apply our results to a system of convex minimization problems.

\section{Preliminaries and Lemmas}

In this section, we give some useful preliminaries and lemmas which will be used in the sequel.

Let $E$ be a real Banach space and let $U=\{x \in E:\|x\|=1\}$ be the unit sphere of $E$. A Banach space $E$ is said to be strictly convex if for any $x, y \in U$,

$$
x \neq y \text { implies }\|x+y\|<2 .
$$

A Banach space $E$ is said to be uniformly convex if, for each $\varepsilon \in(0,2]$, there exists $\delta>0$ such that for any $x, y \in U$,

$$
\|x-y\| \geq \varepsilon \text { implies }\|x+y\|<2(1-\delta) .
$$

It is known that a uniformly convex Banach space is reflexive and strictly convex. The function $\delta:[0,2] \rightarrow[0,1]$ which is called the modulus of convexity of $E$ is defined as follows:

$$
\delta(\varepsilon)=\inf \left\{1-\left\|\frac{x+y}{2}\right\|: x, y \in E,\|x\|=\|y\|=1,\|x-y\| \geq \varepsilon\right\}
$$

Then $E$ is uniformly convex if and only if $\delta(\varepsilon)>0$ for all $\varepsilon \in(0,2]$. A Banach space $E$ is said to be smooth if the limit

$$
\lim _{t \rightarrow 0} \frac{\|x+t y\|-\|x\|}{t}
$$


exists for all $x, y \in U$. It is also said to be uniformly smooth if the limit (2.4) is attained uniformly for $x, y \in U$. The duality mapping $J: E \rightarrow 2^{E^{*}}$ is defined by

$$
J(x)=\left\{x^{*} \in E^{*}:\left\langle x, x^{*}\right\rangle=\|x\|^{2}=\left\|x^{*}\right\|^{2}\right\}
$$

for all $x \in E$. It is also known that if $E$ is uniformly smooth, then $J$ is uniformly norm-to-norm continuous on bounded subsets of $E$ (see [32] for more details).

Let $E$ be a smooth Banach space. The function $\phi: E \times E \rightarrow \mathbb{R}$ is defined by

$$
\phi(x, y)=\|x\|^{2}-2\langle x, J y\rangle+\|y\|^{2}
$$

for all $x, y \in E$. From the definition of $\phi$, we see that

$$
\begin{gathered}
(\|x\|-\|y\|)^{2} \leq \phi(x, y) \leq(\|x\|+\|y\|)^{2}, \\
\phi(x, y)=\phi(x, z)+\phi(z, y)+2\langle x-z, J z-J y\rangle
\end{gathered}
$$

for all $x, y, z \in E$.

Let $C$ be a closed and convex subset of $E$, and let $T$ be a mapping from $C$ into itself. A point $p$ in $C$ is said to be an asymptotic fixed point of $T$ [33] if $C$ contains a sequence $\left\{x_{n}\right\}$ which converges weakly to $p$ such that $\lim _{n \rightarrow \infty}\left\|x_{n}-T x_{n}\right\|=0$. The set of asymptotic fixed points of $T$ will be denoted by $\widehat{F}(T)$. A mapping $T$ is said to be relatively nonexpansive [33, 34] if $\widehat{F}(T)=F(T)$ and $\phi(p, T x) \leq \phi(p, x)$ for all $p \in F(T)$ and $x \in C$. A point $p$ in $C$ is said to be a strong asymptotic fixed point of $T$ if $C$ contains a sequence $\left\{x_{n}\right\}$ which converges strongly to $p$ such that $\lim _{n \rightarrow \infty}\left\|x_{n}-T x_{n}\right\|=0$. The set of strong asymptotic fixed points of $T$ will be denoted by $\widetilde{F}(T)$. A mapping $T$ is said to be weak relatively nonexpansive [35] if $\widetilde{F}(T)=$ $F(T)$ and $\phi(p, T x) \leq \phi(p, x)$ for all $p \in F(T)$ and $x \in C$. It is obvious by definition that the class of weak relatively nonexpansive mappings contains the class of relatively nonexpansive mappings. Indeed, for any mapping $T: C \rightarrow C$, we see that $F(T) \subset \widetilde{F}(T) \subset \widehat{F}(T)$. Therefore, if $T$ is a relatively nonexpansive mapping, then $F(T)=\widetilde{F}(T)=\widehat{F}(T)$.

Nontrivial examples of weak relatively nonexpansive mappings which are not relatively nonexpansive can be found in [36].

Let $E$ be a reflexive, strictly convex and smooth Banach space, and let $C$ be a nonempty, closed, and convex subset of E. The generalized projection mapping, introduced by Alber [37], is a mapping $\Pi_{C}: E \rightarrow C$, that assigns to an arbitrary point $x \in E$ the minimum point of the function $\phi(y, x)$, that is, $\Pi_{C}(x)=\bar{x}$, where $\bar{x}$ is the solution to the minimization problem

$$
\phi(\bar{x}, x)=\min \{\phi(y, x): y \in C\}
$$

In a Hilbert space, $\Pi_{C}$ is coincident with the metric projection denoted by $P_{C}$.

Lemma 2.1 (see [38]). Let E be a uniformly convex and smooth Banach space and let $\left\{x_{n}\right\},\left\{y_{n}\right\}$ be two sequences in $E$. If $\lim _{n \rightarrow \infty} \phi\left(x_{n}, y_{n}\right)=0$ and either $\left\{x_{n}\right\}$ or $\left\{y_{n}\right\}$ is bounded, then $\lim _{n \rightarrow \infty} \| x_{n}-$ $y_{n} \|=0$. 
Lemma 2.2 (see $[37,38]$ ). Let $C$ be a nonempty, closed, and convex subset of a smooth, strictly convex and reflexive Banach space $E$, let $x \in E$ and let $z \in C$. Then $z=\Pi_{C}(x)$ if and only if $\langle y-z, J x-J z\rangle \leq 0$ for all $y \in C$.

Lemma 2.3 (see [37, 38]). Let C be a nonempty, closed, and convex subset of a smooth, strictly convex, and reflexive Banach space E. Then

$$
\phi\left(x, \Pi_{C} y\right)+\phi\left(\Pi_{C} y, y\right) \leq \phi(x, y) \quad \forall x \in C, y \in E
$$

Lemma 2.4 (see [39]). Let E be a smooth and strictly convex Banach space, and let $C$ be a nonempty, closed, and convex subset of $E$. Let $T$ be a mapping from $C$ into itself such that $F(T)$ is nonempty and $\phi(u, T x) \leq \phi(u, x)$ for all $(u, x) \in F(T) \times C$. Then $F(T)$ is closed and convex.

Let $E$ be a reflexive, strictly convex, and smooth Banach space. It is known that $A$ : $E \rightarrow 2^{E^{*}}$ is maximal monotone if and only if $R(J+\lambda A)=E^{*}$ for all $\lambda>0$, where $R(B)$ stands for the range of $B$.

Define the resolvent of $A$ by $J_{\lambda A}=(J+\lambda A)^{-1} J$ for all $\lambda>0$. It is known that $J_{\lambda A}$ is a single-valued mapping from $E$ to $D(A)$ and $A^{-1}\left(0^{*}\right)=F\left(J_{\lambda A}\right)$ for all $\lambda>0$. For each $\lambda>0$, the Yosida approximation of $A$ is defined by

$$
A_{\curlywedge}(x)=\frac{1}{\lambda}\left(J(x)-J J_{\lambda A}(x)\right)
$$

for all $x \in E$. We know that $A_{\curlywedge}(x) \in A\left(J_{\lambda A}(x)\right)$ for all $\lambda>0$ and $x \in E$.

Lemma 2.5 (see [5]). Let $E$ be a smooth, strictly convex, and reflexive Banach space, let $A \subset E \times E^{*}$ be a maximal monotone operator with $A^{-1}\left(0^{*}\right) \neq \emptyset$, and let $J_{\lambda A}=(J+\lambda A)^{-1} J$ for each $\lambda>0$. Then

$$
\phi\left(p, J_{\lambda A}(x)\right)+\phi\left(J_{\lambda A}(x), x\right) \leq \phi(p, x)
$$

for all $\lambda>0, p \in A^{-1}\left(0^{*}\right)$, and $x \in E$.

Lemma 2.6 (see[40]). Let $C$ be a closed and convex subset of a smooth, strictly convex, and reflexive Banach space $E$, let $F$ be a bifunction from $C \times C$ to $\mathbb{R}$ satisfying (A1)-(A4), and let $r>0$ and $x \in E$. Then, there exists $z \in C$ such that

$$
F(z, y)+\frac{1}{r}\langle y-z, J z-J x\rangle \geq 0, \quad \forall y \in C .
$$

Lemma 2.7 (see [41]). Let $C$ be a closed and convex subset of a uniformly smooth, strictly convex, and reflexive Banach space $E$, and let $F$ be a bifunction from $C \times C$ to $\mathbb{R}$ satisfying (A1)-(A4). For all $r>0$ and $x \in E$, define the mapping $T_{r}: E \rightarrow C$ as follows:

$$
T_{r}(x)=\left\{z \in C: F(z, y)+\frac{1}{r}\langle y-z, J z-J x\rangle \geq 0, \forall y \in C\right\} .
$$


Then, the following holds:

(1) $T_{r}$ is single-valued;

(2) $T_{r}$ is a firmly nonexpansive-type mapping [42], that is, for all $x, y \in E$,

$$
\left\langle T_{r} x-T_{r} y, J T_{r} x-J T_{r} y\right\rangle \leq\left\langle T_{r} x-T_{r} y, J x-J y\right\rangle
$$

(3) $F\left(T_{r}\right)=\mathrm{EP}(F)$;

(4) $\mathrm{EP}(F)$ is closed and convex.

Lemma 2.8 (see [41]). Let $C$ be a closed and convex subset of a smooth, strictly, and reflexive Banach space $E$, let $F$ be a bifunction from $C \times C$ to $\mathbb{R}$ satisfying (A1)-(A4), let $r>0$. Then

$$
\phi\left(p, T_{r} x\right)+\phi\left(T_{r} x, x\right) \leq \phi(p, x)
$$

for all $x \in E$ and $p \in F\left(T_{r}\right)$.

\section{Strong Convergence Theorems}

In this section, we are now ready to prove our main theorem.

Theorem 3.1. Let $E$ be a uniformly smooth and uniformly convex Banach space, and let $C$ be a nonempty, closed and convex subset of $E$. Let $A_{i}: E \rightarrow 2^{E^{*}}(i=1,2, \ldots, N)$ be maximal monotone operators, let $F: C \times C \rightarrow \mathbb{R}$ be a bifunction, and let $T_{i}: C \rightarrow C(i=1,2, \ldots)$ be weak relatively nonexpansive mappings such that $\mathcal{F}:=\left[\bigcap_{i=1}^{N} A_{i}^{-1}\left(0^{*}\right)\right] \cap\left[\bigcap_{i=1}^{\infty} F\left(T_{i}\right)\right] \cap E P(F) \neq \emptyset$. Let $\left\{e_{n}\right\}_{n=1}^{\infty} \subset E$ be the sequence such that $\lim _{n \rightarrow \infty} e_{n}=0$. Define the sequence $\left\{x_{n}\right\}_{n=1}^{\infty}$ in $C$ as follows:

$$
\begin{gathered}
x_{1} \in C_{1}=C, \\
y_{n}=J_{\lambda_{n}^{N} A_{N}} \circ J_{\lambda_{n}^{N-1} A_{N-1}}^{N} \cdots \circ J_{\lambda_{n}^{1} A_{1}}\left(x_{n}+e_{n}\right), \\
u_{n}=T_{r_{n}} y_{n}, \\
C_{n+1}=\left\{z \in C_{n}: \sup _{i \geq 1} \phi\left(z, T_{i} u_{n}\right) \leq \phi\left(z, x_{n}+e_{n}\right)\right\}, \\
x_{n+1}=\prod_{C_{n+1}}\left(x_{1}\right), \quad \forall n \geq 1 .
\end{gathered}
$$

If $\liminf _{n \rightarrow \infty} \lambda_{n}^{i}>0$ for each $i=1,2, \ldots, N$ and $\liminf _{n \rightarrow \infty} r_{n}>0$, then the sequence $\left\{x_{n}\right\}$ converges strongly to $q=\Pi_{\mathcal{F}}\left(x_{1}\right)$.

Proof. We split the proof into several steps as follows.

Step 1. $₹ \subset C_{n}$ for all $n \geq 1$.

From Lemma 2.4, we know that $\bigcap_{i=1}^{\infty} F\left(T_{i}\right)$ is closed and convex. From Lemma 2.7(4), we also know that $\operatorname{EP}(F)$ is closed and convex. On the other hand, since $A_{i}(i=1,2, \ldots, N)$ are maximal monotone, $A_{i}^{-1}\left(0^{*}\right)$ are closed and convex for each $i=1,2, \ldots, N$; consequently, $\bigcap_{i=1}^{N} A_{i}^{-1}\left(0^{*}\right)$ is closed and convex. Hence $\mathcal{F}$ is a nonempty, closed, and convex subset of $C$. 
We next show that $C_{n}$ is closed and convex for all $n \geq 1$. Obviously, $C_{1}=C$ is closed and convex. Now suppose that $C_{k}$ is closed and convex for some $k \in \mathbb{N}$. Then, for each $z \in C_{k}$ and $i \geq 1$, we see that $\phi\left(z, T_{i} u_{k}\right) \leq \phi\left(z, x_{k}\right)$ is equivalent to

$$
2\left\langle z, J x_{k}\right\rangle-2\left\langle z, J T_{i} u_{k}\right\rangle \leq\left\|x_{k}\right\|^{2}-\left\|T_{i} u_{k}\right\|^{2} .
$$

By the construction of the set $C_{k+1}$, we see that

$$
\begin{aligned}
C_{k+1} & =\left\{z \in C_{k}: \sup _{i \geq 1} \phi\left(z, T_{i} u_{k}\right) \leq \phi\left(z, x_{k}\right)\right\} \\
& =\bigcap_{i=1}^{\infty}\left\{z \in C_{k}: \phi\left(z, T_{i} u_{k}\right) \leq \phi\left(z, x_{k}\right)\right\} .
\end{aligned}
$$

Hence, $C_{k+1}$ is closed and convex. This shows, by induction, that $C_{n}$ is closed and convex for all $n \geq 1$. It is obvious that $\mathcal{F} \subset C_{1}=C$. Now, suppose that $\mathscr{F} \subset C_{k}$ for some $k \in \mathbb{N}$. For any $p \in \mathcal{F}$, by Lemmas 2.5 and 2.8 , we have

$$
\begin{aligned}
& \phi\left(p, T_{i} u_{k}\right) \leq \phi\left(p, u_{k}\right)=\phi\left(p, T_{r_{k}} y_{k}\right) \\
& \leq \phi\left(p, y_{k}\right) \\
& =\phi\left(p, J_{\lambda_{k}^{N} A_{N}} \circ J_{\lambda_{k}^{N-1} A_{N-1}} \circ \cdots \circ J_{\lambda_{k}^{1} A_{1}}\left(x_{k}+e_{k}\right)\right) \\
& \leq \phi\left(p, J_{\lambda_{k}^{N-1} A_{N-1}} \circ J_{\lambda_{k}^{N-2} A_{N-2}} \circ \cdots \circ J_{\lambda_{k}^{1} A_{1}}\left(x_{k}+e_{k}\right)\right) \\
& \vdots \\
& \leq \phi\left(p, J_{\lambda_{k}^{2} A_{2}} \circ J_{\lambda_{k}^{1} A_{1}}\left(x_{k}+e_{k}\right)\right) \\
& \leq \phi\left(p, J_{\lambda_{k}^{1} A_{1}}\left(x_{k}+e_{k}\right)\right) \\
& \leq \phi\left(p, x_{k}+e_{k}\right) \text {. }
\end{aligned}
$$

This shows that $\mp \subset C_{k+1}$. By induction, we can conclude that $\mathcal{F} \subset C_{n}$ for all $n \geq 1$.

Step 2. $\lim _{n \rightarrow \infty} \phi\left(x_{n}, x_{1}\right)$ exists.

From $x_{n}=\Pi_{C_{n}}\left(x_{1}\right)$ and $x_{n+1}=\Pi_{C_{n+1}}\left(x_{1}\right) \in C_{n+1} \subset C_{n}$, we have

$$
\phi\left(x_{n}, x_{1}\right) \leq \phi\left(x_{n+1}, x_{1}\right), \quad \forall n \geq 1 .
$$

From Lemma 2.3, for any $p \in \mathcal{F} \subset C_{n}$, we have

$$
\phi\left(x_{n}, x_{1}\right)=\phi\left(\Pi_{C_{n}}\left(x_{1}\right), x_{1}\right) \leq \phi\left(p, x_{1}\right)-\phi\left(p, x_{n}\right) \leq \phi\left(p, x_{1}\right) .
$$

Combining (3.5) and (3.6), we conclude that $\lim _{n \rightarrow \infty} \phi\left(x_{n}, x_{1}\right)$ exists. 
Step 3. $\lim _{n \rightarrow \infty}\left\|J\left(T_{i} y_{n}\right)-J\left(x_{n}+e_{n}\right)\right\|=0$.

Since $x_{m}=\Pi_{C_{m}}\left(x_{1}\right) \in C_{m} \subset C_{n}$ for $m>n \geq 1$, by Lemma 2.3, it follows that

$$
\begin{aligned}
\phi\left(x_{m}, x_{n}\right)=\phi\left(x_{m}, \Pi_{C_{n}}\left(x_{1}\right)\right) & \leq \phi\left(x_{m}, x_{1}\right)-\phi\left(\Pi_{C_{n}}\left(x_{1}\right), x_{1}\right) \\
& =\phi\left(x_{m}, x_{1}\right)-\phi\left(x_{n}, x_{1}\right) .
\end{aligned}
$$

Letting $m, n \rightarrow \infty$, we have $\phi\left(x_{m}, x_{n}\right) \rightarrow 0$. By Lemma 2.1, it follows that $\left\|x_{m}-x_{n}\right\| \rightarrow 0$ as $m, n \rightarrow \infty$. Therefore, $\left\{x_{n}\right\}$ is a Cauchy sequence. By the completeness of the space $E$ and the closedness of $C$, we can assume that $x_{n} \rightarrow q \in C$ as $n \rightarrow \infty$. In particular, we obtain that

$$
\lim _{n \rightarrow \infty}\left\|x_{n+1}-x_{n}\right\|=0
$$

Since $e_{n} \rightarrow 0$, we have

$$
\lim _{n \rightarrow \infty}\left\|x_{n+1}-\left(x_{n}+e_{n}\right)\right\|=0
$$

Since $x_{n+1}=\Pi_{C_{n+1}}\left(x_{1}\right) \in C_{n+1}$, for each $i \geq 1$,

$$
\begin{aligned}
\phi\left(x_{n+1}, T_{i} u_{n}\right) & \leq \phi\left(x_{n+1}, x_{n}+e_{n}\right) \\
& =\left\langle x_{n+1}, J\left(x_{n+1}\right)-J\left(x_{n}+e_{n}\right)\right\rangle+\left\langle x_{n+1}-\left(x_{n}+e_{n}\right), J\left(x_{n+1}\right)\right\rangle .
\end{aligned}
$$

Since $E$ is uniformly smooth, $J$ is uniformly norm-to-norm continuous on bounded sets. It follows from (3.9) and by the boundedness of $\left\{x_{n}\right\}$ that

$$
\lim _{n \rightarrow \infty} \phi\left(x_{n+1}, T_{i} u_{n}\right)=0
$$

for all $i=1,2, \ldots$. So from Lemma 2.1, we have

$$
\begin{gathered}
\lim _{n \rightarrow \infty}\left\|x_{n+1}-T_{i} u_{n}\right\|=0, \\
\lim _{n \rightarrow \infty}\left\|T_{i} u_{n}-x_{n}\right\|=0,
\end{gathered}
$$

and, since $e_{n} \rightarrow 0$, therefore

$$
\lim _{n \rightarrow \infty}\left\|T_{i} u_{n}-\left(x_{n}+e_{n}\right)\right\|=0,
$$

for all $i=1,2, \ldots$. Since $J$ is uniformly norm-to-norm continuous on bounded subsets of $E$,

$$
\lim _{n \rightarrow \infty}\left\|J\left(T_{i} u_{n}\right)-J\left(x_{n}+e_{n}\right)\right\|=0
$$

for all $i=1,2, \ldots$. 
Journal of Applied Mathematics

Step $4 . \lim _{n \rightarrow \infty}\left\|T_{i} u_{n}-u_{n}\right\|=0$ for all $i=1,2, \ldots$

Denote that $\Theta_{n}^{i}=J_{\lambda_{n}^{i} A_{i}} \circ J_{\lambda_{n}^{i-1} A_{i-1}} \circ \ldots \circ J_{\lambda_{n}^{1} A_{1}}$ for each $i \in\{1,2, \ldots, N\}$ and $\Theta_{n}^{0}=I$ for each $n \geq 1$. We note that $y_{n}=\Theta_{n}^{N}\left(x_{n}+e_{n}\right)$ for each $n \geq 1$.

To this end, we will show that

$$
\lim _{n \rightarrow \infty}\left\|J\left(\Theta_{n}^{i}\left(x_{n}+e_{n}\right)\right)-J\left(\Theta_{n}^{i-1}\left(x_{n}+e_{n}\right)\right)\right\|=0
$$

for all $i=1,2, \ldots, N$.

For any $p \in \mathcal{F}$, by (3.4), we see that

$$
\begin{aligned}
\phi\left(p, \Theta_{n}^{N-1}\left(x_{n}+e_{n}\right)\right) \leq & \phi\left(p, \Theta_{n}^{N-2}\left(x_{n}+e_{n}\right)\right) \\
\leq & \phi\left(p, \Theta_{n}^{N-3}\left(x_{n}+e_{n}\right)\right) \\
& \vdots \\
& \leq \phi\left(p,\left(x_{n}+e_{n}\right)\right) .
\end{aligned}
$$

Since $p \in \mathcal{F}$, by Lemma 2.5 and (3.16), it follows that

$$
\begin{aligned}
\phi\left(y_{n}, \Theta_{n}^{N-1}\left(x_{n}+e_{n}\right)\right) & \leq \phi\left(p, \Theta_{n}^{N-1}\left(x_{n}+e_{n}\right)\right)-\phi\left(p, y_{n}\right) \\
& \leq \phi\left(p,\left(x_{n}+e_{n}\right)\right)-\phi\left(p, y_{n}\right) \\
& \leq \phi\left(p,\left(x_{n}+e_{n}\right)\right)-\phi\left(p, u_{n}\right) \\
& \leq \phi\left(p,\left(x_{n}+e_{n}\right)\right)-\phi\left(p, T_{i} u_{n}\right) \\
& =\left\|x_{n}+e_{n}\right\|^{2}-\left\|T_{i} u_{n}\right\|^{2}-2\left\langle p, J\left(x_{n}+e_{n}\right)-J\left(T_{i} u_{n}\right)\right\rangle .
\end{aligned}
$$

From (3.13) and (3.14), we get that $\lim _{n \rightarrow \infty} \phi\left(y_{n}, \Theta_{n}^{N-1}\left(x_{n}+e_{n}\right)\right)=0$. So we obtain that

$$
\lim _{n \rightarrow \infty}\left\|y_{n}-\Theta_{n}^{N-1}\left(x_{n}+e_{n}\right)\right\|=0
$$

Again, since $p \in \mathcal{F}$,

$$
\begin{aligned}
\phi\left(\Theta_{n}^{N-1}\left(x_{n}+e_{n}\right), \Theta_{n}^{N-2}\left(x_{n}+e_{n}\right)\right) & \leq \phi\left(p, \Theta_{n}^{N-2}\left(x_{n}+e_{n}\right)\right)-\phi\left(p, \Theta_{n}^{N-1}\left(x_{n}+e_{n}\right)\right) \\
& \leq \phi\left(p,\left(x_{n}+e_{n}\right)\right)-\phi\left(p, \Theta_{n}^{N-1}\left(x_{n}+e_{n}\right)\right) \\
& \leq \phi\left(p,\left(x_{n}+e_{n}\right)\right)-\phi\left(p, T_{i} u_{n}\right) .
\end{aligned}
$$

From (3.13) and (3.14), we get that

$$
\lim _{n \rightarrow \infty} \phi\left(\Theta_{n}^{N-1}\left(x_{n}+e_{n}\right), \Theta_{n}^{N-2}\left(x_{n}+e_{n}\right)\right)=0
$$


It also follows that

$$
\lim _{n \rightarrow \infty}\left\|\Theta_{n}^{N-1}\left(x_{n}+e_{n}\right)-\Theta_{n}^{N-2}\left(x_{n}+e_{n}\right)\right\|=0
$$

Continuing in this process, we can show that

$$
\lim _{n \rightarrow \infty}\left\|\Theta_{n}^{N-2}\left(x_{n}+e_{n}\right)-\Theta_{n}^{N-3}\left(x_{n}+e_{n}\right)\right\|=\cdots=\lim _{n \rightarrow \infty}\left\|\Theta_{n}^{1}\left(x_{n}+e_{n}\right)-\left(x_{n}+e_{n}\right)\right\|=0 .
$$

So, we now conclude that

$$
\lim _{n \rightarrow \infty}\left\|\Theta_{n}^{i}\left(x_{n}+e_{n}\right)-\Theta_{n}^{i-1}\left(x_{n}+e_{n}\right)\right\|=0
$$

for each $i=1,2, \ldots, N$. By the uniform norm-to-norm continuity of $J$, we also have

$$
\lim _{n \rightarrow \infty}\left\|J\left(\Theta_{n}^{i}\left(x_{n}+e_{n}\right)\right)-J\left(\Theta_{n}^{i-1}\left(x_{n}+e_{n}\right)\right)\right\|=0
$$

for each $i=1,2, \ldots, N$. Using (3.23), it is easily seen that

$$
\lim _{n \rightarrow \infty}\left\|y_{n}-\left(x_{n}+e_{n}\right)\right\|=0
$$

From $u_{n}=T_{r_{n}} y_{n}$, by Lemma 2.8, it follows that

$$
\begin{aligned}
\phi\left(u_{n}, y_{n}\right) & =\phi\left(T_{r_{n}} y_{n}, y_{n}\right) \\
& \leq \phi\left(p, y_{n}\right)-\phi\left(p, T_{r_{n}} y_{n}\right) \\
& \leq \phi\left(p, x_{n}+e_{n}\right)-\phi\left(p, u_{n}\right) \\
& \leq \phi\left(p, x_{n}+e_{n}\right)-\phi\left(p, T_{i} u_{n}\right) .
\end{aligned}
$$

This implies that $\lim _{n \rightarrow \infty} \phi\left(u_{n}, y_{n}\right)=0$ and hence

$$
\lim _{n \rightarrow \infty}\left\|u_{n}-y_{n}\right\|=0
$$

Combining (3.13), (3.25), and (3.27), we obtain that

$$
\lim _{n \rightarrow \infty}\left\|T_{i} u_{n}-u_{n}\right\|=0
$$

for all $i \geq 1$.

Step 5. $q \in \bigcap_{i=1}^{\infty} F\left(T_{i}\right)$.

Since $x_{n} \rightarrow q$ and $e_{n} \rightarrow 0, x_{n}+e_{n} \rightarrow q$. So from (3.25) and (3.27), we have $u_{n} \rightarrow q$. Note that $T_{i}(i=1,2, \ldots)$ are weak relatively nonexpansive. Using (3.28), we can conclude that $q \in \tilde{F}\left(T_{i}\right)=F\left(T_{i}\right)$ for all $i \geq 1$. Hence $q \in \bigcap_{i=1}^{\infty} F\left(T_{i}\right)$. 
Step 6. $q \in \bigcap_{i=1}^{N} A_{i}^{-1}\left(0^{*}\right)$.

Noting that $\Theta_{n}^{i}\left(x_{n}+e_{n}\right)=J_{\lambda_{n}^{i} A_{i}} \Theta_{n}^{i-1}\left(x_{n}+e_{n}\right)$ for each $i=1,2, \ldots, N$, we obtain that

$$
\left\|A_{\lambda_{n}^{i}} \Theta_{n}^{i-1}\left(x_{n}+e_{n}\right)\right\|=\frac{1}{\lambda_{n}^{i}}\left\|J\left(\Theta_{n}^{i-1}\left(x_{n}+e_{n}\right)\right)-J\left(\Theta_{n}^{i}\left(x_{n}+e_{n}\right)\right)\right\| .
$$

From (3.24) and $\liminf _{n \rightarrow \infty} \lambda_{n}^{i}>0$, we have

$$
\lim _{n \rightarrow \infty}\left\|A_{\lambda_{n}^{i}} \Theta_{n}^{i-1}\left(x_{n}+e_{n}\right)\right\|=0
$$

We note that $\left(\Theta_{n}^{i}\left(x_{n}+e_{n}\right), A_{\lambda_{n}^{i}} \Theta_{n}^{i-1}\left(x_{n}+e_{n}\right)\right) \in G\left(A_{i}\right)$ for each $i=1,2, \ldots, N$. If $\left(w, w^{*}\right) \in G\left(A_{i}\right)$ for each $i=1,2, \ldots, N$, then it follows from the monotonicity of $A_{i}$ that

$$
\left\langle w^{*}-A_{\lambda_{n}^{i}} \Theta_{n}^{i-1}\left(x_{n}+e_{n}\right), w-\Theta_{n}^{i}\left(x_{n}+e_{n}\right)\right\rangle \geq 0 .
$$

We see that $\Theta_{n}^{i}\left(x_{n}+e_{n}\right) \rightarrow q$ for each $i=1,2, \ldots, N$. Thus, from (3.30) and (3.31), we have

$$
\left\langle w^{*}, w-q\right\rangle \geq 0
$$

By the maximality of $A_{i}$, it follows that $q \in A_{i}^{-1}\left(0^{*}\right)$ for each $i=1,2, \ldots, N$. Therefore, $q \in$ $\bigcap_{i=1}^{N} A_{i}^{-1}\left(0^{*}\right)$.

Step 7. $q \in \mathrm{EP}(F)$.

From $u_{n}=T_{r_{n}} y_{n}$, we have

$$
F\left(u_{n}, y\right)+\frac{1}{r_{n}}\left\langle y-u_{n}, J u_{n}-J y_{n}\right\rangle \geq 0, \quad \forall y \in C
$$

By (A2), we have

$$
\begin{aligned}
\left\|y-u_{n}\right\| \frac{\left\|J u_{n}-J y_{n}\right\|}{r_{n}} & \geq \frac{1}{r_{n}}\left\langle y-u_{n}, J u_{n}-J y_{n}\right\rangle \\
& \geq-F\left(u_{n}, y\right) \geq F\left(y, u_{n}\right), \quad \forall y \in C .
\end{aligned}
$$

Note that $\left\|J u_{n}-J y_{n}\right\| / r_{n} \rightarrow 0$ since $\liminf _{n \rightarrow \infty} r_{n}>0$. From (A4) and $u_{n} \rightarrow q$, we get $F(y, q) \leq 0$ for all $y \in C$. For $0<t<1$ and $y \in C$, define that $y_{t}=t y+(1-t) q$. Then $y_{t} \in C$, which implies that $F\left(y_{t}, q\right) \leq 0$. From (A1), we obtain that $0=F\left(y_{t}, y_{t}\right) \leq t F\left(y_{t}, y\right)+(1-$ t) $F\left(y_{t}, q\right) \leq t F\left(y_{t}, y\right)$. Thus, $F\left(y_{t}, y\right) \geq 0$. From (A3), we have $F(q, y) \geq 0$ for all $y \in C$. Hence, $q \in \operatorname{EP}(F)$. From Steps 5, 6, and 7, we now can conclude that $q \in \mathcal{F}$.

Step 8. $q=\Pi_{\mp}\left(x_{1}\right)$.

From $x_{n}=\Pi_{C_{n}}\left(x_{1}\right)$, we have

$$
\left\langle J\left(x_{1}\right)-J\left(x_{n}\right), x_{n}-z\right\rangle \geq 0, \quad \forall z \in C_{n} .
$$


Since $\mathcal{F} \subset C_{n}$, we also have

$$
\left\langle J\left(x_{1}\right)-J\left(x_{n}\right), x_{n}-z\right\rangle \geq 0, \quad \forall z \in \mathcal{F} .
$$

Letting $n \rightarrow \infty$ in (3.36), we obtain that

$$
\left\langle J\left(x_{1}\right)-J(q), q-z\right\rangle \geq 0, \quad \forall z \in \mathcal{F} .
$$

This shows that $q=\Pi_{\mathcal{F}}\left(x_{1}\right)$ by Lemma 2.2. We thus complete the proof.

As a direct consequence of Theorem 3.1, we can also apply to a system of convex minimization problems.

Theorem 3.2. Let $E$ be a uniformly smooth and uniformly convex Banach space, and let $C$ be a nonempty, closed, and convex subset of $E$. Let $f_{i}: E \rightarrow(-\infty, \infty](i=1,2, \ldots, N)$ be proper lower semicontinuous convex functions, let $F: C \times C \rightarrow \mathbb{R}$ be a bifunction, and let $T_{i}: C \rightarrow C(i=$ $1,2, \ldots)$ be weak relatively nonexpansive mappings such that $\mathcal{F}:=\left[\bigcap_{i=1}^{N}\left(\partial f_{i}^{-1}\right)\left(0^{*}\right)\right] \cap\left[\bigcap_{i=1}^{\infty} F\left(T_{i}\right)\right] \cap$ $E P(F) \neq \emptyset$. Let $\left\{e_{n}\right\}_{n=1}^{\infty} \subset E$ be the sequence such that $\lim _{n \rightarrow \infty} e_{n}=0$. Define the sequence $\left\{x_{n}\right\}_{n=1}^{\infty}$ in $C$ as follows:

$$
\begin{gathered}
x_{1} \in C_{1}=C, \\
z_{n}^{1}=\arg \min _{y \in E}\left\{f_{1}(y)+\frac{1}{2 \lambda_{n}^{1}}\|y\|^{2}+\frac{1}{\lambda_{n}^{1}}\left\langle y, J\left(x_{n}+e_{n}\right)\right\rangle\right\}, \\
\vdots \\
z_{n}^{N-1}=\arg \min _{y \in E}\left\{f_{N-1}(y)+\frac{1}{2 \lambda_{n}^{N-1}}\|y\|^{2}+\frac{1}{\lambda_{n}^{N-1}}\left\langle y, J\left(z_{n}^{N-2}\right)\right\rangle\right\}, \\
y_{n}=\arg \min _{y \in E}\left\{f_{N}(y)+\frac{1}{2 \lambda_{n}^{N}}\|y\|^{2}+\frac{1}{\lambda_{n}^{N}}\left\langle y, J\left(z_{n}^{N-1}\right)\right\rangle\right\}, \\
u_{n}=T_{r_{n}} y_{n}, \\
C_{n+1}=\left\{z \in C_{n}: \sup _{i \geq 1} \phi\left(z, T_{i} u_{n}\right) \leq \phi\left(z, x_{n}+e_{n}\right)\right\}, \\
x_{n+1}=\prod_{C_{n+1}}\left(x_{1}\right), \quad \forall n \geq 1 .
\end{gathered}
$$

If $\lim \inf _{n \rightarrow \infty} \lambda_{n}^{i}>0$ for each $i=1,2, \ldots, N$ and $\liminf _{n \rightarrow \infty} r_{n}>0$, then the sequence $\left\{x_{n}\right\}$ converges strongly to $q=\Pi_{\mathcal{F}}\left(x_{1}\right)$. 
Proof. By Rockafellar's theorem [43, 44], $\partial f_{i}$ are maximal monotone operators for each $i=$ $1,2, \ldots, N$. Let $\lambda^{i}>0$ for each $i=1,2, \ldots, N$. Then, $z^{i}=J_{\lambda^{i} \partial f_{i}}(x)$ if and only if

$$
\begin{aligned}
0 & \in \partial f_{i}\left(z^{i}\right)+\frac{1}{\lambda^{i}}\left(J\left(z^{i}\right)-J(x)\right) \\
& =\partial\left(f_{i}+\frac{1}{\lambda^{i}}\left(\frac{\|\cdot\|^{2}}{2}-J(x)\right)\right)\left(z^{i}\right),
\end{aligned}
$$

which is equivalent to

$$
z^{i}=\arg \min _{y \in E}\left\{f_{i}(y)+\frac{1}{\lambda^{i}}\left(\frac{\|y\|^{2}}{2}-\langle y, J(x)\rangle\right)\right\}
$$

Using Theorem 3.1, we thus complete the proof.

If $E=H$ is a real Hilbert space, we then obtain the following results.

Corollary 3.3. Let $C$ be a nonempty, closed and convex subset of a real Hilbert space $H$. Let $A_{i}: H \rightarrow$ $2^{H}(i=1,2, \ldots, N)$ be maximal monotone operators, let $F: C \times C \rightarrow \mathbb{R}$ be a bifunction, and let $T_{i}: C \rightarrow C(i=1,2, \ldots)$ be weak relatively nonexpansive mappings such that $\mathcal{F}:=\left[\bigcap_{i=1}^{N} A_{i}^{-1}(0)\right] \cap$ $\left[\bigcap_{i=1}^{\infty} F\left(T_{i}\right)\right] \cap E P(F) \neq \emptyset$. Let $\left\{e_{n}\right\}_{n=1}^{\infty} \subset H$ be the sequence such that $\lim _{n \rightarrow \infty} e_{n}=0$. Define the sequence $\left\{x_{n}\right\}_{n=1}^{\infty}$ in $C$ as follows:

$$
\begin{aligned}
& x_{1} \in C_{1}=C \text {, } \\
& y_{n}=J_{\lambda_{n}^{N} A_{N}} \circ J_{\lambda_{n}^{N-1} A_{N-1}} \circ \cdots \circ J_{\lambda_{n}^{1} A_{1}}\left(x_{n}+e_{n}\right), \\
& u_{n}=T_{r_{n}} y_{n} \\
& C_{n+1}=\left\{z \in C_{n}: \sup _{i \geq 1}\left\|z-T_{i} u_{n}\right\| \leq\left\|z-\left(x_{n}+e_{n}\right)\right\|\right\}, \\
& x_{n+1}=P_{C_{n+1}}\left(x_{1}\right), \quad \forall n \geq 1 .
\end{aligned}
$$

If $\liminf _{n \rightarrow \infty} \lambda_{n}^{i}>0$ for each $i=1,2, \ldots, N$ and $\liminf _{n \rightarrow \infty} r_{n}>0$, then the sequence $\left\{x_{n}\right\}$ converges strongly to $q=P_{\mp}\left(x_{1}\right)$.

Corollary 3.4. Let $C$ be a nonempty, closed, and convex subset of a real Hilbert space $H$. Let $f_{i}: H \rightarrow$ $(-\infty, \infty](i=1,2, \ldots, N)$ be proper lower semi-continuous convex functions, let $F: C \times C \rightarrow \mathbb{R}$ be a bifunction, and let $T_{i}: C \rightarrow C(i=1,2, \ldots)$ be weak relatively nonexpansive mappings such 
that $\mathcal{F}:=\left[\bigcap_{i=1}^{N}\left(\partial f_{i}^{-1}\right)(0)\right] \cap\left[\bigcap_{i=1}^{\infty} F\left(T_{i}\right)\right] \cap E P(F) \neq \emptyset$. Let $\left\{e_{n}\right\}_{n=1}^{\infty} \subset H$ be the sequence such that $\lim _{n \rightarrow \infty} e_{n}=0$. Define the sequence $\left\{x_{n}\right\}_{n=1}^{\infty}$ in $C$ as follows:

$$
\begin{gathered}
x_{1} \in C_{1}=C, \\
z_{n}^{1}=\arg \min _{y \in H}\left\{f_{1}(y)+\frac{1}{2 \lambda_{n}^{1}}\|y\|^{2}+\frac{1}{\lambda_{n}^{1}}\left\langle y, x_{n}+e_{n}\right\rangle\right\}, \\
\vdots \\
z_{n}^{N-1}=\arg \min _{y \in H}\left\{f_{N-1}(y)+\frac{1}{2 \lambda_{n}^{N-1}}\|y\|^{2}+\frac{1}{\lambda_{n}^{N-1}}\left\langle y, z_{n}^{N-2}\right\rangle\right\}, \\
y_{n}=\arg \min _{y \in H}\left\{f_{N}(y)+\frac{1}{2 \lambda_{n}^{N}}\|y\|^{2}+\frac{1}{\lambda_{n}^{N}}\left\langle y, z_{n}^{N-1}\right\rangle\right\}, \\
u_{n}=T_{r_{n}} y_{n}, \\
C_{n+1}=\left\{z \in C_{n}: \sup _{i \geq 1}\left\|z-T_{i} u_{n}\right\| \leq\left\|z-\left(x_{n}+e_{n}\right)\right\|\right\}, \\
x_{n+1}=P_{C_{n+1}}\left(x_{1}\right), \quad \forall n \geq 1 .
\end{gathered}
$$

If $\liminf \operatorname{in}_{n \rightarrow \infty} \lambda_{n}^{i}>0$ for each $i=1,2, \ldots, N$ and $\liminf _{n \rightarrow \infty} r_{n}>0$, then the sequence $\left\{x_{n}\right\}$ converges strongly to $q=P_{\mp}\left(x_{1}\right)$.

Remark 3.5. Using the shrinking projection method, we can construct a hybrid-proximal point algorithm for solving a system of the zero-finding problems, the equilibrium problems, and the fixed point problems of weak relatively nonexpansive mappings.

Remark 3.6. Since every relatively nonexpansive mapping is weak relatively nonexpansive, our results also hold if $T_{i}: C \rightarrow C(i=1,2, \ldots)$ are relatively nonexpansive mappings.

\section{Acknowledgments}

The authors thank the editor and the referee(s) for valuable suggestions. The first author was supported by the Thailand Research Fund, the Commission on Higher Education, and the University of Phayao under Grant MRG5380202. The second and the third authors wish to thank the Thailand Research Fund and the Centre of Excellence in Mathematics, Thailand.

\section{References}

[1] P. Cholamjiak, Y. J. Cho, and S. Suantai, "Composite iterative schemes for maximal monotone operators in reflexive Banach spaces," Fixed Point Theory and Applications, vol. 2011, article 7, 10 pages, 2011.

[2] Y. J. Cho, S. M. Kang, and H. Zhou, "Approximate proximal point algorithms for finding zeroes of maximal monotone operators in Hilbert spaces," Journal of Inequalities and Applications, vol. 2008, Article ID 598191, 10 pages, 2008.

[3] L.-C. Ceng, Y.-C. Liou, and E. Naraghirad, "Iterative approaches to find zeros of maximal monotone operators by hybrid approximate proximal point methods," Fixed Point Theory and Applications, vol. 2011, Article ID 282171, 18 pages, 2011. 
[4] O. Güler, "On the convergence of the proximal point algorithm for convex minimization," SIAM Journal on Control and Optimization, vol. 29, no. 2, pp. 403-419, 1991.

[5] F. Kohsaka and W. Takahashi, "Strong convergence of an iterative sequence for maximal monotone operators in a Banach space," Abstract and Applied Analysis, no. 3, pp. 239-249, 2004.

[6] G. Marino and H.-K. Xu, "Convergence of generalized proximal point algorithms," Communications on Pure and Applied Analysis, vol. 3, no. 4, pp. 791-808, 2004.

[7] N. Onjai-uea and P. Kumam, "A new iterative scheme for equilibrium problems, fixed point problems for nonexpansive mappings and maximal monotone operators," Fixed Point Theory and Applications. In press.

[8] X. Qin, S. M. Kang, and Y. J. Cho, "Approximating zeros of monotone operators by proximal point algorithms," Journal of Global Optimization, vol. 46, no. 1, pp. 75-87, 2010.

[9] S. Saewan and P. Kumam, "A hybrid iterative scheme for a maximal monotone operator and two countable families of relatively quasi-nonexpansive mappings for generalized mixed equilibrium and variational inequality problems," Abstract and Applied Analysis, vol. 2010, Article ID 123027, 31 pages, 2010.

[10] P. Sunthrayuth and P. Kumam, "A system of generalized mixed equilibrium problems, maximal monotone operators, and fixed point problems with application to optimization problems," Abstract and Applied Analysis, vol. 2012, Article ID 316276, 39 pages, 2012.

[11] K. Wattanawitoon and P. Kumam, "Hybrid proximal-point methods for zeros of maximal monotone operators, variational inequalities and mixed equilibrium problems," International Journal of Mathematics and Mathematical Sciences, vol. 2011, Article ID 174796, 31 pages, 2011.

[12] K. Wattanawitoon and P. Kumam, "Generalized mixed equilibrium problems for maximal monotone operators and two relatively quasi-nonexpansive mappings," Thai Journal of Mathematics, vol. 9, no. 1, pp. 171-195, 2011.

[13] K. Wattanawitoon and P. Kumam, "A new iterative scheme for generalized mixed equilibrium, variational inequality problems and a zero point of maximal monotone operators," Journal of Applied Mathematics, vol. 2012, Article ID 692829, 27 pages, 2012.

[14] U. Witthayarat, Y. J. Cho, and P. Kumam, "Convergence of an iterative algorithm for common solutions for zeros of maximal accretive operator with applications," Journal of Applied Mathematics, vol. 2012, Article ID 185104, 17 pages, 2012.

[15] Y. Yao and M. A. Noor, "On convergence criteria of generalized proximal point algorithms," Journal of Computational and Applied Mathematics, vol. 217, no. 1, pp. 46-55, 2008.

[16] Y. Yao and N. Shahzad, "Strong convergence of a proximal point algorithm with general errors," Optimization Letters, vol. 6, no. 4, pp. 621-628, 2012.

[17] B. Martinet, "Régularisation d'inéquations variationnelles par approximations successives," vol. 4, no. R-3, pp. 154-158, 1970.

[18] R. T. Rockafellar, "Monotone operators and the proximal point algorithm," SIAM Journal on Control and Optimization, vol. 14, no. 5, pp. 877-898, 1976.

[19] S. Kamimura and W. Takahashi, "Approximating solutions of maximal monotone operators in Hilbert spaces," Journal of Approximation Theory, vol. 106, no. 2, pp. 226-240, 2000.

[20] S. Kamimura, F. Kohsaka, and W. Takahashi, "Weak and strong convergence theorems for maximal monotone operators in a Banach space," Set-Valued Analysis, vol. 12, no. 4, pp. 417-429, 2004.

[21] W. Takahashi and K. Zembayashi, "Strong convergence theorem by a new hybrid method for equilibrium problems and relatively nonexpansive mappings," Fixed Point Theory and Applications, vol. 2008, Article ID 528476, 11 pages, 2008.

[22] W. Takahashi, Y. Takeuchi, and R. Kubota, "Strong convergence theorems by hybrid methods for families of nonexpansive mappings in Hilbert spaces," Journal of Mathematical Analysis and Applications, vol. 341, no. 1, pp. 276-286, 2008.

[23] P. Cholamjiak, "A hybrid iterative scheme for equilibrium problems, variational inequality problems, and fixed point problems in Banach spaces," Fixed Point Theory and Applications, vol. 2009, Article ID 719360, 18 pages, 2009.

[24] P. Cholamjiak and S. Suantai, "Convergence analysis for a system of equilibrium problems and a countable family of relatively quasi-nonexpansive mappings in Banach spaces," Abstract and Applied Analysis, vol. 2010, Article ID 141376, 17 pages, 2010.

[25] W. Cholamjiak and S. Suantai, "A hybrid method for a countable family of multivalued maps, equilibrium problems, and variational inequality problems," Discrete Dynamics in Nature and Society, vol. 2010, Article ID 349158, 14 pages, 2010. 
[26] W. Cholamjiak and S. Suantai, "A new hybrid algorithm for a countable family of quasi-nonexpansive mappings and equilibrium problems," Journal of Nonlinear and Convex Analysis, vol. 12, no. 2, pp. 381398, 2011.

[27] P. Kumam, "A hybrid approximation method for equilibrium and fixed point problems for a monotone mapping and a nonexpansive mapping," Nonlinear Analysis. Hybrid Systems, vol. 2, no. 4, pp. 1245-1255, 2008.

[28] P. Kumam, "A new hybrid iterative method for solution of equilibrium problems and fixed point problems for an inverse strongly monotone operator and a nonexpansive mapping," Journal of Applied Mathematics and Computing, vol. 29, no. 1-2, pp. 263-280, 2009.

[29] X. Qin, Y. J. Cho, and S. M. Kang, "Convergence theorems of common elements for equilibrium problems and fixed point problems in Banach spaces," Journal of Computational and Applied Mathematics, vol. 225, no. 1, pp. 20-30, 2009.

[30] Y. Shehu, "Iterative approximation method for finite family of relatively quasi nonexpansive mappings and systems of equilibrium problems," Journal of Global Optimization, vol. 51, no. 1, pp. 69-78, 2011.

[31] Y. Shehu, "A new hybrid iterative scheme for countable families of relatively quasi-nonexpansive mappings and system of equilibrium problems," International Journal of Mathematics and Mathematical Sciences, vol. 2011, Article ID 131890, 23 pages, 2011.

[32] W. Takahashi, Nonlinear Functional Analysis, Fixed Point Theory and Its Application, Yokohama Publishers, Yokohama, Japan, 2000.

[33] D. Butnariu, S. Reich, and A. J. Zaslavski, "Asymptotic behavior of relatively nonexpansive operators in Banach spaces," Journal of Applied Analysis, vol. 7, no. 2, pp. 151-174, 2001.

[34] D. Butnariu, S. Reich, and A. J. Zaslavski, "Weak convergence of orbits of nonlinear operators in reflexive Banach spaces," Numerical Functional Analysis and Optimization. An International Journal, vol. 24, no. 5-6, pp. 489-508, 2003.

[35] H. Zegeye and N. Shahzad, "Strong convergence theorems for monotone mappings and relatively weak nonexpansive mappings," Nonlinear Analysis. Theory, Methods E Applications, vol. 70, no. 7, pp. 2707-2716, 2009.

[36] Y. Su, H.-K. Xu, and X. Zhang, "Strong convergence theorems for two countable families of weak relatively nonexpansive mappings and applications," Nonlinear Analysis. Theory, Methods $\mathcal{E}$ Applications, vol. 73, no. 12, pp. 3890-3906, 2010.

[37] Y. I. Alber, "Metric and generalized projection operators in Banach spaces: properties and applications," in Theory and Applications of Nonlinear Operators of Accretive and Monotone Type, A. G. Kartsatos, Ed., vol. 178, pp. 15-50, Marcel Dekker, New York, NY, USA, 1996.

[38] S. Kamimura and W. Takahashi, "Strong convergence of a proximal-type algorithm in a Banach space," SIAM Journal on Optimization, vol. 13, no. 3, pp. 938-945, 2002.

[39] S.-Y. Matsushita and W. Takahashi, "A strong convergence theorem for relatively nonexpansive mappings in a Banach space," Journal of Approximation Theory, vol. 134, no. 2, pp. 257-266, 2005.

[40] E. Blum and W. Oettli, "From optimization and variational inequalities to equilibrium problems," The Mathematics Student, vol. 63, no. 1-4, pp. 123-145, 1994.

[41] W. Takahashi and K. Zembayashi, "Strong and weak convergence theorems for equilibrium problems and relatively nonexpansive mappings in Banach spaces," Nonlinear Analysis. Theory, Methods $\mathcal{E}$ Applications, vol. 70, no. 1, pp. 45-57, 2009.

[42] F. Kohsaka and W. Takahashi, "Existence and approximation of fixed points of firmly nonexpansivetype mappings in Banach spaces," SIAM Journal on Optimization, vol. 19, no. 2, pp. 824-835, 2008.

[43] R. T. Rockafellar, "Characterization of the subdifferentials of convex functions," Pacific Journal of Mathematics, vol. 17, pp. 497-510, 1966.

[44] R. T. Rockafellar, "On the maximal monotonicity of subdifferential mappings," Pacific Journal of Mathematics, vol. 33, pp. 209-216, 1970. 


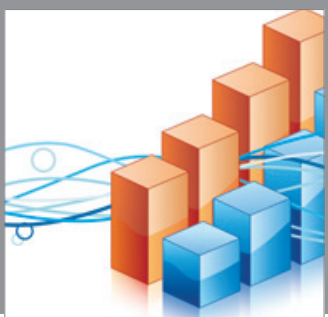

Advances in

Operations Research

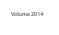

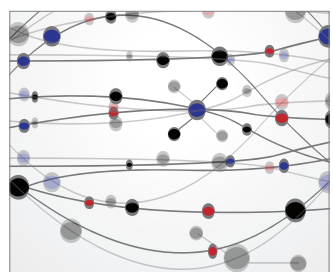

\section{The Scientific} World Journal
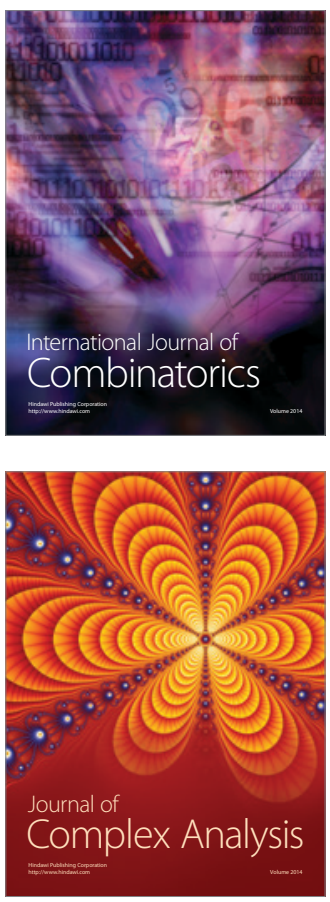

International Journal of

Mathematics and

Mathematical

Sciences
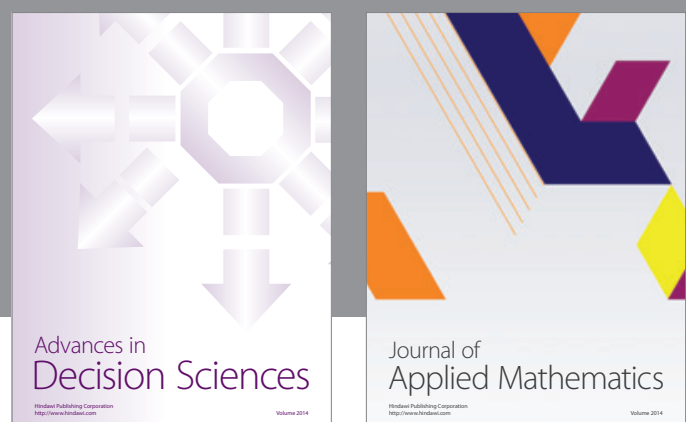

Journal of

Applied Mathematics
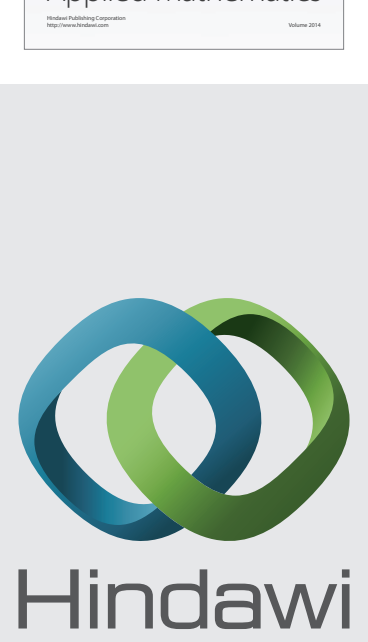

Submit your manuscripts at http://www.hindawi.com
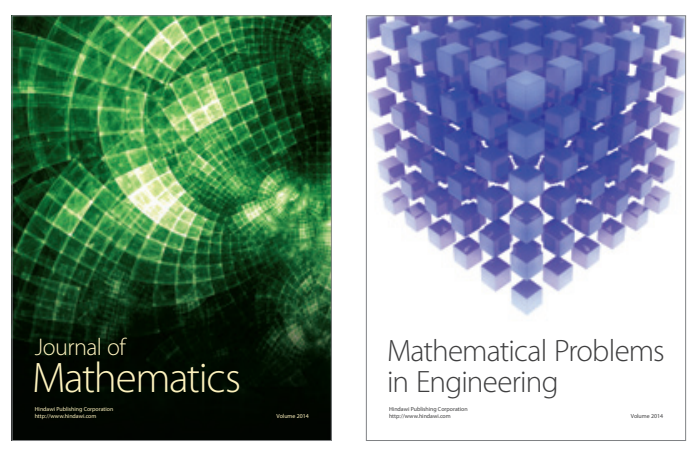

Mathematical Problems in Engineering
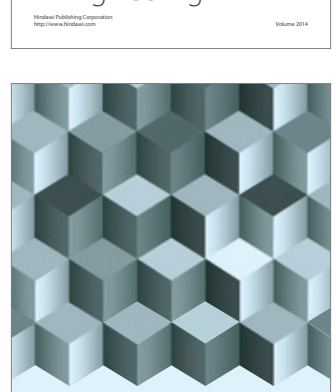

Journal of

Function Spaces
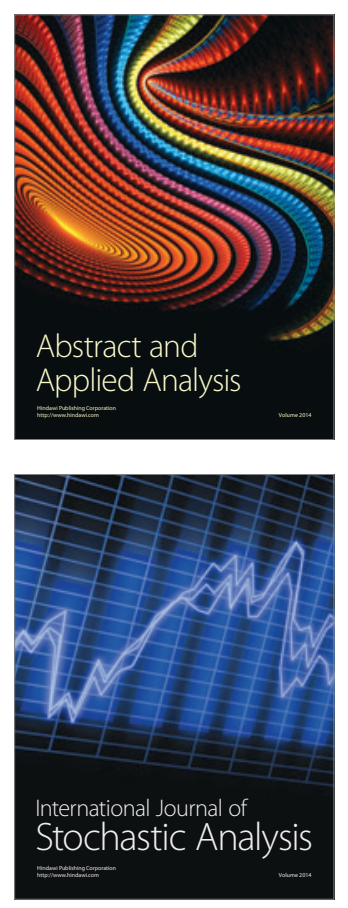

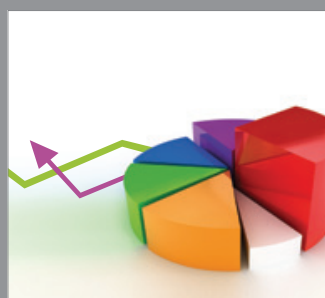

ournal of

Probability and Statistics

Promensencen
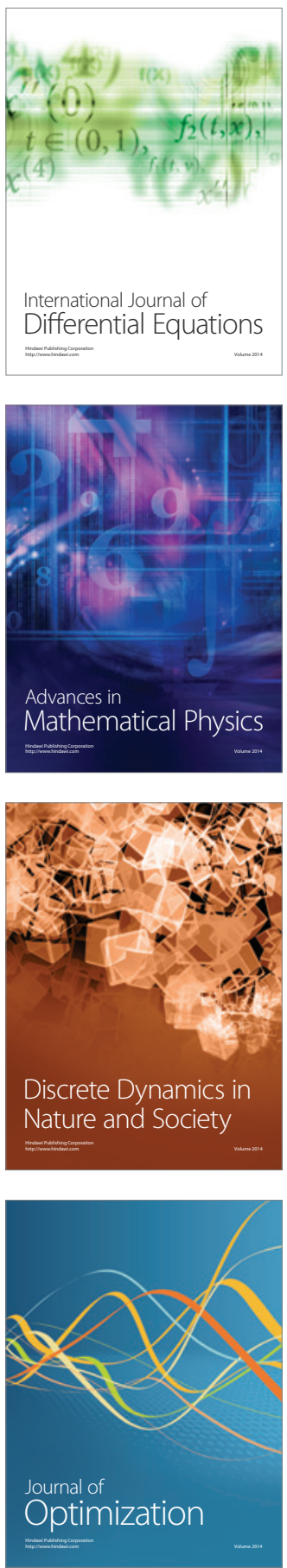